\title{
A relação privado / público em Hannah Arendt e Eric Weil*
}

\author{
Le rapport prive/public chez Hannah Arendt et Eric Weil
}

The private/public report at Hannah Arendt and Eric Weil

DOI: $10.20873 / \mathrm{rpv} 6 \mathrm{n} 2-15$

\section{Patrice Canivez}

Orcid: 0000-0001-8105-5051

E-mail: patrice.canivez@univ-lille.fr

Tradução

Ubiratane de Morais Rodrigues** Orcid: 0000-0001-8101-9616 Email: ubiratanerodrigues@gmail.com

A diferença entre privado e público é desenvolvida principalmente, por Hannah Arendt, na obra $A$ condição humana. Essa diferença é tematizada a partir de uma análise da cidade antiga, e por assim dizer categorizada, no sentido de que essa diferença permite realizar uma certa leitura da história. Digamos provisoriamente que o privado e o público se distinguem por meio de uma série de oposições e que essas oposições, marcantes na Antiguidade, se deslocaram ou se dissolveram - especialmente nos tempos modernos. Estamos interessados nessa distinção na medida em que ela nos leva a identificar pontos em comum - pontos de concordância, pontos

\footnotetext{
${ }^{*}$ Artigo publicado originalmente em alemão com o título Über die Beziehungen zwischen dem Privaten und dem Öffentlichen bei H. Arendt und E. Weil. In: Perspektiven der Philosophie, Band 15, 1989, p. 161-189.

** Professor Adjunto II de Filosofia pela Universidade Federal do Maranhão (UFMA). Doutor em Filosofia pela Universidade de São Paulo (USP).
} 
de discussão - com a teoria de Eric Weil. Essas convergências devem nos permitir formular os problemas ligados à situação moderna do indivíduo, devem também nos levar a apreender as divergências profundas entre duas orientações, por assim dizer, simétricas do pensamento. 0 confronto entre a fenomenologia arendtiana e a filosofia reflexiva e formal de Weil nos leva a vislumbrar o problema da relação da reflexão com o concreto, que neste caso é o da vida no Estado: o problema metodológico está ligado ao problema político.

Uma primeira oposição característica é aquela da natureza e da liberdade. 0 privado é o domínio da natureza: é no privado que o indivíduo se liberta da necessidade natural, ou seja, cuida das suas próprias necessidades e das necessidades ligadas à reprodução. É o domínio da família, da relação do homem com a mulher, com os escravos e, portanto, também do trabalho. O homem é livre quando está livre dessas necessidades naturais e, portanto, quando está livre do próprio privado: ele vive fora, em um domínio exposto à luz da publicidade, onde o que é real não é o que é produzido e consumido, mas essencialmente o que é visto, ouvido e conservado na memória. Este espaço público é, portanto, um espaço político que proporciona um palco para o discurso e para a ação, que são atividades retiradas das finalidades biológicas, isto é, livres, portadoras e criadoras de seus próprios sentidos. Isso não lhes é imposto de fora, não lhes é preexistente, nem lógica nem cronologicamente. Assim, a realidade do discurso e da ação depende de dois aspectos fundamentais: por um lado, são inovadores, não dedutíveis de uma necessidade ou de um princípio "científico" - não há política científica - e a ação é comparável a um nascimento, ela revela uma identidade imprevisível; por outro lado, aparecem aos olhos de uma pluralidade e diversidade de indivíduos livres, capazes de lembrá-los. A realidade do discurso ativo, da ação política, é sua manifestação e não sua necessidade, seu enraizamento no processo da natureza. Aqueles que permanecem incluídos neste processo - mulheres e escravos - continuam, portanto, dentro dos limites do privado.

Esta primeira aproximação permite ver a importância da propriedade. 0 cidadão é aquele para quem uma certa riqueza, isto é, um certo domínio da natureza, permite uma atividade que não tem mais a subsistência, a vida biológica como fonte. Pode-se ver, no entanto, que o privado não tem apenas um significado negativo em relação ao público. Ele tem um certo 
significado: o privado é a privação das faculdades mais elevadas e humanas (ARENDT, 1983, p. 48), começando com a liberdade. Mas também tem o sentido de condição de possibilidade do domínio público, ele é essencial para o político que não se reduz ao vital. E antes de tudo como riqueza privada: a riqueza privada tornou-se "condição de admissão à vida pública, não porque seu possuidor trabalhasse para acumulá-la, mas pelo contrário, porque razoavelmente ela garantia que esse proprietário não teria que se dedicar à aquisição de seus meios de consumo, de forma que fosse livre para se dedicar às atividades públicas" (ARENDT, 1983, p. 76). Mas essa relação entre as duas esferas não exclui sua "impermeabilidade": "se o proprietário decidisse aumentar seus bens em vez de gastá-los na condução de uma vida política, seria como se estivesse sacrificando sua liberdade para se tornar voluntariamente o que o escravo foi contra a sua vontade: um ser sujeito à necessidade" (ARENDT, 1983, p. 77). Pelo contrário, é uma característica da modernidade solicitar ao Estado, ao político, que seja um instrumento a serviço do aumento ou da proteção da propriedade privada, ou ainda, da commonwealth, isto é, da riqueza comum. 0 paradoxo constitutivo dessa perspectiva moderna é que os indivíduos têm em comum seus interesses privados e não mais essa coisa pública que floresce à parte ou além desses interesses. Paradoxalmente, mais uma vez, a propriedade é melhor preservada no Estado antigo, ou na compreensão antiga do político, precisamente na medida em que não é o princípio de uma acumulação indefinida e, por conseguinte, de expropriação e de troca. Isso nos apresenta o segundo aspecto desse sentido positivo do privado em relação ao público: do ponto de vista exterior, a propriedade privada é o lugar que eu ocupo no mundo, aquele que me situa e cuja permanência, a casa, o domínio, materializa a permanência da família, garante a sua existência e a minha aos olhos dos outros, na configuração estável, concreta e objetivamente durável da cidade: é a "condição política elementar do pertencimento ao mundo" (ARENDT, 1983, p. 285). No mundo moderno, a propriedade, sujeita ao processo de acumulação e de troca, tornou-se um objeto de consumo. Ela não me instala mais na duração, tornou-se um objeto transitório no processo de minha própria vida e é essa redução do significado político e antropológico da propriedade que torna possível a ideia de sua abolição. 0 comunismo é, portanto, uma passagem ao limite, uma extrapolação de um processo característico da modernidade, e seus 
oponentes liberais não são fundamentalmente diferentes dele neste ponto do significado político do privado: o princípio da livre acumulação contém o da expropriação. Em ambos os lados, a equação entre propriedade e consumo é realizada: por uma parte, eu só tenho que possuir o que consumo, o que significa que, em última análise, eu realmente possuo apenas meu próprio corpo; por outra parte, deve-se possuir e deve-se poder possuir cada vez mais, caso contrário os processos de produção e consumo se enfraquecem.

Estamos desde já, aqui, no centro de um problema fundamental colocado pela teoria de Arendt, o das relações entre o político e o econômico, de que a extensão do conceito de economia se restringe às dimensões do doméstico e do oikos, ou estendido às dimensões da vida coletiva como um todo. É claro que Hannah Arendt procura proteger a ação de qualquer tipo de interesse material, econômico, privado, ou seja, de toda utilidade; esta ação é absolutamente livre, é energia (ARENDT, 1983, p. 232), carrega consigo o seu próprio fim. Uma das razões da admiração de Hannah Arendt pela revolução húngara de 1956, na qual ela vê uma das raras emergências da política na modernidade, é que "a questão do pão não desempenhou nenhum papel”. Tratava-se de um movimento inteiramente político, voltado para a liberdade, ninguém tendo "sequer sonhado em retroceder nas profundas transformações sociais que o regime comunista havia instaurado no país" (ARENDT apud. ENEGRÉN, p. 132). 0 político, portanto, exclui o econômico, há uma dicotomia radical entre polis e oikos. No entanto, este ponto está aberto para discussão. Em primeiro lugar, presume-se que Arendt se refere, antes, à Atenas de Péricles, ou mesmo a de Clístenes, do que à do século IV a.C. onde é necessário contar com os misthos ecclesiasticos para preencher os passos da Pnyx. A teoria pressupõe, portanto, uma periodização de épocas propriamente políticas, ainda que ela se construa, a partir de dados históricos, uma espécie de tipo-ideal. Mas, deixando de lado essa periodização, a dicotomia entre o econômico e o político é motivo de debate entre os próprios historiadores. Assim, Moses I. Finley, em Politics in the Ancient World, escreve: “O Estado é o lugar onde os interesses conflitantes se chocam, o lugar dos conflitos de classe. Nenhum grego, nenhum romano teria contestado isso, mesmo se (bastante semelhante a seus homólogos modernos) eles muitas vezes dissessem 
o contrário em debates políticos" (FINLEY, 1985, p. 23). Mas um eco diferente viria do próprio Weil e, em particular, da categoria da discussão na Lógica da Filosofia. Weil de fato assume, e da maneira mais clara, o oposto da descrição arendtiana. 0 mundo da cidade

é o da propriedade e a função cívica fundada na propriedade [...]. 0 cidadão é proprietário, e como tal é funcionário, porque a propriedade é a base da função social [...]. Mas a importância da propriedade para a função é correspondida pela importância da função para a propriedade. Como membro do órgão que decide, como magistrado que dirige e distribui, o cidadão é o representante da comunidade e, como tal, tem por sua vez a propriedade de todos, uma vez que forma e aplica a lei. Ser rico e poderoso são os dois objetivos do cidadão, e um não pode ser obtido sem o outro: sem 'meios' ele não adquirirá o poder, sem ele não os manterá. (WEIL, 1950a, p. 125-126)

A oposição natureza-liberdade leva em Arendt a toda uma série de distinções intimamente ligadas umas às outras, de modo que é um tanto arbitrário agrupá-las ou abstrair algumas delas. No entanto, várias observações podem ser feitas em torno de duas distinções fundamentais, uma opondo a temporalidade cíclica da natureza à temporalidade linear do público, a outra opondo o homem à singularidade do indivíduo.

Vemos que, para Hannah Arendt, e em sua referência à Antiguidade, o essencial é que os processos vitais, biológicos, precisamente os de produção e consumo, estejam contidos nos limites precisos que são os do setor privado. Esses limites têm o duplo sentido de conter a exuberância do vital e protegê-lo. Quaisquer que sejam os significados privativos do privado continua a ser essencial, como vimos, mas não são apenas as atividades que aí ocorrem que são essenciais, também é importante que ocorram na sombra e na obscuridade características do lar e, a fortiori para alguns deles, no segredo da privacidade. Algumas coisas precisam ser

\footnotetext{
${ }^{1}$ Moses I. Finley abre seu livro com estas citações de Aristóteles: "A tirania é uma monarquia cujo objeto é o interesse do monarca; o objetivo da oligarquia são os interesses dos ricos; a democracia dos pobres"; "[...] a soberania de uma minoria ou de uma maioria é apenas um acidente, peculiar quer às oligarquias, quer às democracias, porque em toda a parte os ricos estão em minoria e os pobres em maioria [...]. A verdadeira diferença entre democracia e oligarquia é a pobreza e a riqueza" (Política, III, 1279 b 6-40). Sobre o uso do conceito de "classe", ver o trabalho citado de Finley, p. 32. Além disso, no que se refere ao problema da "periodização" da política ou das referências históricas da análise da cidade, eis o que escreve André Enegrén: "é claro que o horizonte determinante da teoria de Arendt não é a Atenas de Péricles, sendo a cidade menos uma referência histórica a ser encontrada do que o índice de uma época exemplar. É através da linguagem de seus políticos e poetas que a isonomia da cidade atesta essencialmente 'a verdade deslumbrante de sua harmonia nativa'” (ARENDT, 1983, p. 249, nota 1).
} 
escondidas para existir. 0 mesmo é verdade para a vida corporal, mas também para certos sentimentos como o amor, que é por natureza estranho-ao-mundo e condenado a perecer se exposto à luz da publicidade (ARENDT, 1983, p. 62 e 272-273). Observações semelhantes podem ser feitas sobre a noção cristã de bondade, que traz tão pouca luz que, idealmente, deveria escapar da própria consciência de seu autor (ARENDT, 1983, p. 86)². Portanto, existe ao mesmo tempo em Arendt, um elogio constante do espaço público e uma profunda ligação com o privado, que é também o lugar privilegiado da reflexão e da compreensão. 0 que se manifesta no discurso de Copenhague, proferido em 1975 por ocasião do recebimento do Prêmio Sonnig:

meu próprio temperamento e inclinações, essas qualidades psíquicas inatas que de outra forma determinam os julgamentos que formamos após a reflexão, pelo menos nossos preconceitos e nossos primeiros movimentos instintivos prefeririam me encorajar a fugir do domínio público por timidez. Isso talvez seja o que parecerá falso e inautêntico para quem conhece alguns de meus livros e se lembra do elogio, mesmo da desculpa que neles se faz do domínio público como um espaço de aparências que é o único adequado para o discurso e para a ação política. Quando se trata de teorizar e compreender, os meros espectadores colocados acima do corpo a corpo* muitas vezes têm uma visão mais aguda e profunda do significado real dos eventos do que os participantes que estão, como deveriam estar, imersos no calor do momento. Na verdade, é perfeitamente possível compreender a política e pensar sobre ela sem ser o que chamamos de um animal político. (ARENDT, 1982, p. 2425)

No entanto, quaisquer que sejam as nuances da topologia arendtiana, estas não colocam fundamentalmente em questão o fato de que o privado é posto sob o signo do biológico, e sua temporalidade própria é a temporalidade cíclica da vida, da qual Nietzsche faz uma projeção magistral com a noção do eterno retorno. 0 trabalho é utilizado para a reprodução, tanto das minhas próprias forças como das de outros seres vivos, há um momento no metabolismo do homem com a natureza, um processo que se repete incessantemente, que consome o que produz e que tende sempre a expandir-se mais, porque produz sempre mais e intensifica ainda mais o consumo. Há, portanto, uma metáfora biológica que se impõe aqui: o ciclo produçãoconsumo não é apenas repetitivo, mas exuberante, dotado de uma vitalidade que, depois de ter

\footnotetext{
${ }^{2}$ Cf. Mt 6, 3-4
}

${ }^{*}$ Aqui, Arendt faz referência a mêlée, expressão que remete a lances do jogo de rugby nos quais vários jogadores das diferentes equipes se enfrentam procurando recuperar a bola. (Nota do Tradutor). 
destruído as fronteiras do setor privado, invadiu quase completamente, nos tempos modernos, o espaço público. Nesse ciclo, a coisa singular é bastante efêmera, ela só aparece como um momento ou como um exemplo de seu gênero. 0 objeto de "consumo cotidiano" é desprovido de singularidade, quase desaparece no instante mesmo em que ele aparece. 0 próprio homem, neste processo, não pode se agarrar a nada que não seja transitório, há apenas um momento no processo de geração, que diz respeito ao gênero e não à individualidade. Isso está incluído em sua "geração", desta vez no sentido sociológico do termo. 0 que o especifica é a média, o comportamento médio desta geração. Apreendido pelo aspecto biológico, sou um ser de necessidades e sou suficientemente definido quando visto em relação às necessidades e comportamentos modais da espécie. Para que eu tenha uma identidade, é preciso separar um começo e um fim desse ciclo, e esse nascimento e essa morte devem se inscrever na permanência de um mundo, na temporalidade linear de um mundo concreto, de um mundo de objetos duráveis que me precedem e sobrevivem a mim. Este mundo é um mundo de configurações estáveis e eminentemente humanas. Não é a natureza bruta, é o mundo dos objetos, das cidades, das obras do homo faber em oposição aos produtos do trabalho e do animal laborans. A própria configuração da cidade, resultante da obra de um legislador artesão, tem, por sua subsistência, o significado de uma quase-imortalidade. A sua durabilidade inteiramente espacial é a condição de possibilidade da minha humanidade porque a humanidade é o que escapa, o que se liberta da repetitividade fluida dos vivos. 0 espaço público é, portanto, um palco, e este palco é fundamentalmente um mundo de obras, de coisas, que acolhe e possibilita a atividade política, porque situa indivíduos que estão ao mesmo tempo separados e conectados pela espacialidade e objetividade deste mundo. É neste palco público que, à luz do que é visto e ouvido por todos, o indivíduo escapa ao caráter transitório da vida. $\mathrm{O}$ que eu faço e o que digo existe porque é reconhecido e dura porque está guardado na memória. A vida do indivíduo se especifica pelo discurso e pela ação, que são essencialmente reveladores da sua identidade singular porque essencialmente criadores, trazendo à luz algo novo. À palavra ativa que não tem outra finalidade senão ela mesma porque visa a beleza da ação e da própria palavra, revela essa singularidade que se perde quando se assenta na coisa, e que está mais presente no discurso do que na coisa dita. No 
entanto, ela sobrevive sozinha na história, na biografia pela qual escapa da uniformidade da zoê.

O espaço público, como espaço de aparências, é, portanto, fundamentalmente, o que me permite existir como ser humano, porque existência e manifestação coincidem: existir é estar entre os homens, inter homines esse. Por outro lado, nada se evapora mais facilmente da existência do que as experiências mais íntimas e privadas, como, por exemplo, a da dor, a mais difícil de dizer, a mais rebelde à exposição. Mas essas características antropológicas do espaço público levam a requisitos políticos específicos. 0 espaço político exige uma pluralidade de iguais. Não uma pluralidade de indivíduos que são a repetição do mesmo que na natureza ou na massa moderna - o que a torna tão acessível às estatísticas - mas uma pluralidade de diferenças e pontos de vista que coexistem em igualdade. No espaço público, o cidadão está no meio de seus pares. 0 reconhecimento só é válido porque é um reconhecimento gratuito, nem um dom divino, nem o serviço prestado pelo subordinado ao seu superior. Além disso, o público difere do privado por ignorar a hierarquia. Não há política em sentido estrito, exceto para homens iguais retirados do domínio de um senhor. Estados como a Pérsia, na Antiguidade, onde encontramos essa hierarquia do senhor e dos súditos, são aqueles que transpuseram para o domínio público o domínio do pater familias, uma dominação que será sempre, em última análise, justificada pela natureza, pela necessidade natural, qualquer que seja o conteúdo dado à palavra natureza. Tal dominação exclui a liberdade, não só do dominado, mas também do dominante, porque este último está concretamente vinculado pela relação que estabeleceu, e porque se priva, ou porque está privado, do livre reconhecimento dos outros, sem o qual ele não está seguro de sua própria liberdade. É essa característica peculiar do privado que encontramos na vida pública dos bárbaros ou das tiranias. Podemos colocar de outra forma: a identidade humana que eu me dou e pela qual eu escapei de meu gênero, isto é, minha definição natural, supõe que eu não sou o único como senhor, mas que me distingo. E essa distinção, que se encontra na permanência do ideal agonístico entre os gregos, implica uma comunidade de iguais, o espaço aberto da publicidade em vez do espaço fechado da hierarquia. 
Seria fácil apontar analogias frequentes entre as análises de Arendt e de Weil sobre a fundação do político. Basta lembrar mais uma vez o capítulo da Lógica da Filosofia dedicado à discussão. 0 que é surpreendente é a própria visão espacializante e muito figurativa das coisas que emerge dessas análises. Isso se deve ao estilo e ao método de Arendt, conforme visto em sua interpretação da lei. Essa interpretação parte de uma observação etimológica (cf. ARENDT, 1983, p. 74, nota 4): a lei, nomos, vem de nemein que significa repartir, possuir (o que é assim repartido), residir. A constituição, a lei da cidade, é a cerca, o muro, o círculo como na fundação mítica de Roma, a linha que circunscreve o espaço público, é também a distribuição e a diferença. 0 privado tem o sentido de estar no interior que esconde dos olhares os processos biológicos e do ser, em sua face externa, o lugar que me situa no mundo. A lei, portanto, não é principalmente uma ordem ou proibição, mas a organização do espaço humano do discurso e da ação. Trata-se, portanto, de um pensamento às vezes muito metafórico, o que não significa dizer que a análise seja conceitualmente vacilante. Ao constitucionalismo de Arendt responde Weil: a comunidade política é constituída por uma lei fundamental que rege a troca e o discurso, que em particular estabelece lugares e disposições que dão a esse discurso um status e um valor.

O que é notável, também, é que a análise da temporalidade, ou melhor, das temporalidades, depende intimamente da topologia. 0 tempo deriva seu sentido e sua própria qualidade do lugar onde a atividade ocorre: do tipo de atividade dependendo se se trata do trabalho, da obra, da ação comunicativa ou do discurso ativo, mas também do espaço em que se desenvolve ou que ela desenvolve, da estrutura de apercepção ou do tipo de manifestação que exige ou supõe. Não é indiferente se o indivíduo está sozinho - como na obra do artesão ou no trabalho que remete à solidão das dores corporais - ou com os outros, sob o olhar de seus subordinados ou de seus pares.

Essa "espacialização" parece ser uma pista ou resultado do método fenomenológico de Arendt, da atenção dada à manifestação em que a experiência da existência se resume. Seguindo o título da primeira parte do livro de André Enegrén, trata-se de fato de uma fenomenologia política de que nós trataremos, uma fenomenologia que leva a uma reabilitação, até mesmo a 
uma apologia, do espaço público como espaço de aparências. Ela se envolve, em a Condição humana, como uma "exploração das formas da atividade humana, cuja ambição é descobrir as estruturas que condicionam a existência" (ENEGRÉN, 1984, p. 33). Essas estruturas - trabalho, obra, ação - são a base de toda reflexão sobre a política, mas também sobre as faculdades da mente e os acontecimentos da história. E, ao mesmo tempo, essa elucidação das estruturas da existência ativa é sempre também uma descrição dos tipos de manifestação, apresentação e visibilidade do humano. Essa descrição se dá no horizonte da finitude, percebida como mortalidade, mas também como natalidade, e é a esta última, na medida em que significa atualizar o novo, que a ação política se assemelha ao mais. É também com base neste apego ao mundo e à existência como habitação ${ }^{3}$ que Arendt pode escrever que "a mudança mais radical que podemos imaginar para a condição humana seria a emigração para outro planeta" (ARENDT, 1983, p. 18).

Seja como for, esta oposição entre o público e o privado, que nos leva a peregrinar na Antiguidade, permite-nos apreender, de um determinado ângulo, o todo de uma evolução. Digamos apenas que essa configuração específica da cidade foi derrotada pelo progresso histórico. De fato, podemos observar uma irrupção do social que devora tanto os espaços privados quanto os públicos. 0 social é a publicidade dada ao trabalho e ao vivente: os dois estão intimamente ligados, sendo o trabalho, como aponta Arendt em Marx, o metabolismo do homem com a natureza, algo análogo à procriação, pois se trata de preservar e, na verdade, de reconstituir a própria vida. A sociedade é a publicidade dada ao orgânico, às necessidades e sua satisfação, à produção e ao consumo; é a organização pública administrativa e tecnológica desse metabolismo. É verdade que, entre aqueles que foram chamados de mestres da suspeita, os temas da vida, sob uma ou outra dessas formas de procriação e de trabalho, da força vital e daquilo que ela produz, são onipresentes, o que os torna testemunhas exemplares da época.

\footnotetext{
3 "A vida humana como tal exige um mundo na medida exata em que precisa de um lar na terra durante sua estada aqui" (ARENDT, 1989, p. 268). Este ponto de vista também define a questão da educação. Cf. "La Crise de l'éducation" (ARENDT, 1989, p. 223 ss.).
} 
O espaço privado desaparece, na medida em que é exposto aos olhos de todos: a natureza não define mais o que é meu, onde eu me abrigo e me retiro, mas, ao contrário, é isto que é o objeto do debate e da curiosidade pública. De modo que o privado se reduz às dimensões do íntimo, do interior profundo, ou seja, em última instância ao sentimento como sentimento. Podemos encontrar um primeiro esboço desse movimento no estoicismo. A experiência da dor é a experiência limite, a mais remota do mundo. A dor mais intensa é o extremo da abstração, do retraimento sobre si mesmo; o mundo não é mais perceptível em suas configurações e em sua objetividade, e a ação é suspensa. 0 estoicismo e o epicurismo dão uma prefiguração desse privado restrito à relação consigo mesmo, na qual a felicidade, como lembra Hannah Arendt, é essencialmente a ausência de dor do lema de Epicuro posta em prática: "viver escondido e não se importar com o mundo" (ARENDT, 1983, p. 127). Na modernidade, esse retraimento no íntimo, ao mesmo tempo que um aprofundamento, uma "escavação" da relação consigo mesmo, é particularmente evidente em Rousseau. Ao mesmo tempo, relembraremos, neste autor, tanto a nostalgia da família quanto a problemática do declínio da política. Mas, para além destes exemplos privilegiados, o privado de cada um, centrado no indivíduo, está o tempo livre que é um tempo vazio, um "hiato no ciclo biologicamente condicionado do trabalho" (ARENDT, 1989, p. 263), um tempo que não é o tempo do ócio no sentido antigo, "isto é, o tempo em que estamos livres de todos os cuidados e atividades necessárias ao processo vital e, portanto, livres para o mundo" (ARENDT, 1989, p. 263), mas um tempo preenchido pelo consumo de "produtos culturais", quer dizer, por processos quase biológicos: "o lazer, assim como o trabalho e o sono, faz parte irrevogavelmente do processo biológico da vida. E a vida biológica está sempre, no trabalho ou no repouso, empenhada no consumo ou na receptividade passiva da distração, um metabolismo que se alimenta das coisas devorando-as" (ARENDT, 1989, p. 263).

Ao mesmo tempo que o social corrói o privado, ao mesmo tempo que a economia deixa de ser a arte de administrar seu domínio e sua própria propriedade para se tornar a preocupação central da comunidade, o político é reduzido a uma função da economia e às relações sociais. Isso é comum de se observar, tanto em Marx quanto nos economistas liberais. A análise de Weil concorda com esta descrição: do ponto de vista técnico analisado pela Lógica da Filosofia 
sob a categoria de condição, no capítulo IX, o Estado deve ter funções negativas: defesa de uma determinada sociedade em sua luta com as outras e em particular na guerra com sociedades pré-modernas, polícia interna para evitar que os improdutivos e os associais perturbem a ordem social, regulação da atividade, defesa da possibilidade de cada um ter acesso à propriedade, de acordo com seus talentos e sua energia, isto é, preservação da fonte psicológica de produção e troca. Para os liberais como para Marx, mas por outras razões e por outros meios, a ideia de uma sociedade mundial, perfeitamente regulada porque superados os conflitos ligados à história das comunidades rivais, implica a absorção do Estado: o poder exercido sobre cada pessoa seria fruto de seu próprio interesse, pois isso a vincula à organização racional na qual encontra os meios de satisfação, bem como a fonte de interesses sempre renovados.

Para Arendt, isso significa a absorção da ação e do discurso na produção, consumo e comunicação da informação. 0 indivíduo não age mais, ele tem um comportamento, ele não é mais individualizado por uma biografia, ele é um indivíduo, justamente, um indivíduo em geral situado em relação a uma média, definida pelo jogo da estatística. A permanência do mundo é atacada, devorada pela proliferação de coisas vivas que não estão mais contidas nos confins do privado. A cidade deixa de ser a configuração durável que impõe a linearidade de uma história ao ciclo das gerações, tornando-se uma entidade que se consome e se reproduz. Os bens que se esgotam e que perduram por muito tempo tornam-se bens de consumo que desaparecem com ela. E o político se reduz inteiramente à administração desse gigantesco processo de satisfação e criação de necessidades: a burocracia é a forma especificamente moderna do político, o que dele resta quando é engolido pelo social.

Assim, a evolução adequada da era moderna reformulou a oposição do público e do privado como aquela entre o social e o íntimo. Deve-se notar ainda que essa reformulação produziu uma reversão notável: enquanto o espaço público é originalmente o lugar de distinção, enquanto o indivíduo privado se funde na homogeneidade de uma natureza, a sociedade comercial exclui os homens como homens e como distintos, ela "exige que os homens sejam vistos apenas na privacidade de suas famílias ou na intimidade de seus amigos" (ARENDT, 1983, p. 236). 
Quando se passa das análises de Hannah Arendt para a Filosofia Política de Eric Weil, a primeira constatação é que Weil tirou radicalmente as consequências dessa evolução característica: a oposição fundamental é aquela da sociedade e do indivíduo, e não a da família e da sociedade civil, muito menos a de um espaço político e de um espaço doméstico. Mesmo na análise da cidade grega no capítulo intitulado discussão da Lógica da Filosofia, não encontramos a oposição entre a família e a cidade, mas a relação de implicação recíproca da riqueza, quer dizer, da propriedade e do poder, é tida como fundamento de uma estratégia estritamente individual.

Podemos apreender uma série de diferenças entre os dois autores, sendo uma das mais características a de que passamos de um modelo biológico do social para um modelo materialista e mecanicista ${ }^{4}$. Onde Arendt vê a fluidez e exuberância do processo, Weil descreve mais prontamente o rigor de uma estrutura. Mas uma outra diferença, não menos característica, é que o privado, com Weil, não é um lugar. Nem o é, como em Arendt, na medida em que é reduzido ao íntimo e à incomunicabilidade do sentimento. Mas é originalmente, e a perda dessa origem é uma experiência negativa, pois ela é a perda do mundo: a alienação característica da modernidade não é a alienação de si mesmo, mas do mundo. Em Weil, o privado não pode ser compreendido ou apreendido com a ajuda de uma fenomenologia que examinaria as configurações do mundo para derivar seus significados, ele é o "produto" das contradições do mecanismo social. Mais precisamente, ele é a autoconsciência de si do indivíduo como sujeito livre, à medida que emerge das contradições em que sua existência social o fixa. Este privado tem, portanto, raízes concretas. Mas esse enraizamento concreto é o tempo livre que a sociedade produz exatamente como produz bens materiais e porque ela produz um excedente que pode capitalizar e armazenar. É esse tempo livre, que a sociedade justifica como lazer necessário à reconstituição fisiológica e psicológica do indivíduo, que é, do ponto de vista do próprio indivíduo, a condição existencial de seu sentimento de liberdade, que esse sentimento seja explícito

\footnotetext{
4 Porque é aquele em que a sociedade se interpreta (cf. WEIL, 1956, p. 71-72).
} 
ou presente no modo de insatisfação e de tédio: "o tempo livre [...] é a sua existência como indivíduo que vive para si" (ARENDT, 1983, p. 80).

As contradições do social baseiam-se na contradição entre o universal e o particular, entre o universal da sociedade moderna e o particular da comunidade histórica. Weil, como Arendt, tematiza esse movimento de globalização da sociedade moderna, da extensão da racionalidade do cálculo, do valor regulatório da eficiência, de modos de produção cada vez mais eficientes e racionalizados. É neste contexto de homogeneização que as sociedades modernas agora se destacam, especificadas por suas tradições, história, cultura, língua, interesses herdados do passado, etc. Essa homogeneização é feita em detrimento desses valores tradicionais, pois os submete ao primado do tecnicismo e do progresso. Mas também é importante ressaltar que não se opõe, pura e simplesmente, a essas peculiaridades históricas, uma vez que se apoia nelas. 0 progresso técnico mordisca e relativiza os valores tradicionais, mas ao mesmo tempo os "utiliza". Ele carrega um estilo de vida mais ou menos prejudicial à cultura herdada do passado, mas essa redução também é uma renovação. É por estarem em competição uma com as outras que sociedades particulares se modernizam, e o desafio dessa competição é, se não impor, pelo menos preservar sua identidade, preservar sua diferença. Temas de um certo nacionalismo econômico são suficientemente onipresentes para que a tese de Weil mostre aqui sua relevância. Basta, além disso, pensar no que o progresso deve à tecnologia militar: o impulso dado à pesquisa científica pelas necessidades de armamento das grandes ou superpotências apenas confirma uma observação secular: em questões econômicas como em outras, o universal é produto das lutas e oposições do particular (cf. WEIL, 1991a, p. 273-274).

O que é importante para nós, quer dizer, para o indivíduo privado, é que o indivíduo não pode escolher entre a racionalidade técnica e o valor ou moralidade tradicional, porque ambos se implicam um no outro no mesmo movimento em que se excluem. Sem racionalidade técnica, a sociedade particular morre por razões muito concretas; sem essa particularidade, essa sociedade carece das fontes "psicológicas" essenciais à sua agressividade econômica. Isso, para a consciência do indivíduo, produz as condições daquilo que Weil chama de fixação. 0 indivíduo não pode - exceto em casos excepcionais - identificar-se totalmente com sua função porque as 
peculiaridades históricas da moralidade viva fazem parte das "condições psicológicas de possibilidade" de funcionamento. Nem pode refugiar-se na segurança de uma vida comunitária fundada na certeza moral $^{5}$, não pode ser absorvido na imediatez feliz de um mundo ético, porque esses valores morais são secundários, relativizados, desvalorizados pelos imperativos técnicos. A competição social, em sua face externa, portanto, fixa o indivíduo em uma relação de distanciamento de seus próprios valores. Ele deve acreditar em valores que sabe que são desvalorizados por sua própria prática social. 0 valor tradicional é importante e sério, mas ele é porque é necessário que o seja, o que significa que não é tão sério, o valor sagrado continua sendo o do trabalho.

A competição dentro de uma determinada sociedade produz um distanciamento simétrico do mecanismo social, de modo que o indivíduo se encontra em uma posição de afastamento da racionalidade técnica e funcional, como também da sua tradição. 0 resultado desse duplo distanciamento é o isolamento do indivíduo em sua relação consigo mesmo, a irredutibilidade e o problema do privado.

No que diz respeito à sua organização interna, a sociedade surge para o indivíduo como um sistema de lugares de acesso mais ou menos difícil, mais ou menos raro, que se especificam pela sua importância no mecanismo e pelas vantagens que nele estão associadas - vantagens financeiras ou outras, como tempo livre, etc. Essas funções sociais são tanto mais importantes quanto dotadas de um poder de ação sobre todo o mecanismo, ou seja, um poder de transformação da natureza por meio de um poder sobre outros mecanismos. 0 valor do trabalho individual não é, portanto, medido em termos de tempo de trabalho, nem diretamente em termos de produção. As vantagens não se baseiam no biológico, no sentido de que corresponderiam à reconstituição da força de trabalho, ou seja, à reprodução das forças assim consumidas. Eles se medem pela dificuldade de substituição do indivíduo, ou seja, pela maior ou menor escassez de suas habilidades. É claro, e isso situaria Weil em relação a Arendt, mas também em relação a Marx, que a função social desempenha em Weil o papel que a propriedade desempenha em

\footnotetext{
${ }^{5}$ Sobre o significado estritamente weiliano dessa noção de certeza, cf. WEIL, 1950a, p. 107-120.
} 
Arendt. Assim como a propriedade é o que me situa no mundo em Arendt, a função social é literalmente, para Weil, meu lugar nele. Isso mostra uma diferença radical na apreciação do processo de socialização. Para Arendt, esse processo corresponde a uma alienação do mundo, a uma destruição do mundo, de sua permanência, de suas estruturas, a um engolfamento desse mundo propriamente humano no ciclo de produção e consumo, ou seja, nos processos quase biológicos desse monstruoso ser vivo que é o corpo social (pensa-se no Leviatã de Hobbes). Para Weil, também, a sociedade é uma segunda natureza, pseudo-natureza, mas ela não tem o sentido de reduzir o mundo humano a um fluxo monótono e quase animal. Em vez de dizer que o social é a redução do humano ao natural, dir-se-ia, da perspectiva de Weil, que o social é uma humanização da natureza que se torna matéria, um elemento da atividade humana. Longe de essa pseudo-natureza ser marcada por todos os traços negativos do natural que prevalecem em Arendt, ela é elevada em Weil à categoria de um cosmos humano. Pois, nesta sociedade que é tradicional - em muitos aspectos, variadamente tradicional - e racional, o intelectual se engaja em uma forma moderna de contemplação. Isso também situa Weil em relação a Arendt, para quem a noção de contemplação, de theoria, não tem mais o menor significado. Weil vê uma espécie de retradução da posição do spectator mundi na sociedade moderna. É a do intelectual, que apreende na história próxima ou distante uma pluralidade de "mundos", inteligíveis de acordo com sua intenção fundamental, sua coerência ou os valores em relação aos quais estão organizados, redutíveis a tipos-ideais, mas não hierarquizados porque eles não valem, não para si próprios, mas para a livre inteligência que os compreende a todos porque não escolhe nenhum para si, nem mais uns que os outros. 0 intelectual moderno, pelo menos em sua figura erudita e ataráxica, apreende, à parte das lutas e dos conflitos reais deste mundo, a coerência dos interesses humanos, desde a pequena comunidade ou mundos individuais até as civilizações que eles determinam e que fazem da época, ou da História, uma ou mais constelações inteligíveis. Na pessoa privada de sua compreensão, ele é um espectador desse cosmos humanizado. Em suma, onde Arendt vê principalmente o processo, Weil vê as estruturas do mecanismo social, que podem ser racionalizadas usando a linguagem funcional que analisa a categoria da 
condição na Lógica da Filosofia (WEIL, 1950a, p. 203-232), mas também por essas superestruturas, culturas cuja inteligência gosta de produzir teoria ${ }^{6}$.

O desaparecimento da propriedade, ou a sua redução a um bem transitório, não significa a perda de um mundo e do meu lugar neste mundo, visto que aí ocupo um lugar em virtude da função. Mas é verdade que, se não se está na pura fluidez do processo, as estruturas são abertas e móveis. Elas o são, pelo menos, de direito: os indivíduos são organizados em grupos, identificados por uma comunidade de funções, e o princípio da eficiência exige que a função e o grupo social estejam abertos ao indivíduo apenas com base em suas capacidades. Sendo as funções e os grupos hierárquicos, o princípio é o da máxima mobilidade social, ou seja, os indivíduos, mas também os grupos devem poder subir e descer na hierarquia de acordo com a sua importância, que pode aumentar ou diminuir. Porém, a mobilidade dos indivíduos já é um problema, como nos lembram os sociólogos, embora seja objeto, como valor, de uma espécie de consenso. A mobilidade de grupos, por sua vez, introduz os conflitos em uma determinada sociedade, cuja natureza também é histórica. A hierarquia social tende a se cristalizar e reproduzir, independentemente de mudanças na real importância dos diferentes grupos. Alguns deles estão ocupados em posição inferior àquela que deveriam ocupar de acordo com seu papel efetivo na organização coletiva, outros se sentem ameaçados por essas classes inferiores, correndo o risco de serem rebaixados em relação a elas, também, na valorização de sua própria importância. 0 princípio da luta das classes sociais é, portanto, de ambos os lados, a lacuna entre a avaliação da função, ou do conjunto de funções, e a realidade de seu poder sobre o conjunto do mecanismo social, se esse poder se manifesta em si como administração de negócios ou como gozo de certas vantagens. Esse princípio é o do sentimento de injustiça, e a lacuna ainda pode ser descrita como o estado histórico da distribuição dos poderes sociais e a realidade efetiva dos modos de produção, sendo a medida dessa efetividade a eficiência7.

\footnotetext{
${ }^{6}$ Sobre a inteligência, Cf. DEPADT, 1982; 1984.

${ }^{7}$ Não podemos desenvolver aqui a questão da relação de Weil com Marx. Deve-se fazer referência a WEIL, 1950b, p. 105-116. Cf. também BARAQUIN, 1982 e SALEM, 1984.
} 
A luta das camadas sociais tem um efeito duplo sobre o indivíduo. Como uma luta, ela o joga de volta em sua individualidade natural. Porque é necessário mobilizar o indivíduo contra o estado atual do mecanismo social - sendo este estado ao mesmo tempo a má ordem e / ou a má evolução que ameaça a ordem atual e desejável -, ela apela para o que há nele de associal. Por se efetuar por meio da linguagem, o indivíduo experiencia a realidade do discurso da racionalidade funcional. Essa experiência é que não há um discurso da racionalidade, unívoco e verdadeiro, mas plural. As classes são organizadas para a luta e cada uma dessas organizações usa os mesmos termos para produzir uma teoria social, econômica, técnica, específica e oposta a todas as outras. Para que o significado do discurso racional apareça ao indivíduo, não é a relação com uma realidade objetiva ${ }^{8}$ que resolveria os conflitos sociais como a teoria platônica pretendia resolver os conflitos políticos. Não há ciência social objetiva que possa dissolver esses conflitos enviando os adversários de volta ao equívoco de suas ilusões. E isso não só porque a História não é um objeto, mas em virtude da própria cientificidade do discurso científico moderno, como analisada pela categoria da condição (WEIL, 1950a, p. 203-232). Seu “objeto" é o possível, do qual o evento ou o valor atual da variável são apenas casos especiais; a ação é, portanto, possível, mesmo que o cientista não esteja interessado na ação aqui e agora; seu critério é o sucesso, que pode vir de uma teoria à qual nenhuma configuração objetiva imaginável corresponde. No nível particular da organização das relações humanas, o discurso técnico é, portanto, inevitavelmente sofisticado. 0 seu significado é o poder que confere e, em particular, o poder que confere, com vista à organização da produção, sobre os indivíduos. É por isso que esta organização não é o resultado, inclusive em seus aspectos mais racionalmente eficazes, de um "demiurgo" fora da sociedade, mas dos conflitos que a estruturam. Não podemos, então, reduzir o sofisma, porque não existe um ponto de vista transcendente - nenhum artesão do mecanismo social, nenhum modelo eidético de paz social - que possa substituí-lo. Só podemos compreendê-lo de um ponto de vista mais completo que limita seus desvios, ao mesmo tempo

\footnotetext{
${ }^{8}$ Sobre o significado especificamente weiliano da palavra “objetivo”, veja-se WEIL, 1950a, p. 139-156.
} 
que atribui um sentido ao progresso técnico, e que é o ponto de vista propriamente político (cf. WEIL, 1956, p. 131-224).

Seja como for, o indivíduo percebe que o discurso funcional não é o discurso de algum sujeito. Na melhor das hipóteses, a racionalidade atua sem ele, como um resultado mecânico da luta entre as classes; na pior, ela atua sobre ele. Porque ele manipula os outros no momento em que se dirigem a eles, ele sabe que está sendo manipulado por eles e, manipulado ou ainda objetivado por seu próprio discurso, que não revela um sujeito, mas manifesta uma força. Ele, portanto, se sente ligado à sua função e ao seu grupo. Mas o jogo de funções e grupos, o trabalho e a modificação da organização do trabalho, são um jogo de linguagem que é um jogo de forças, e o resultado dessas forças concorrentes, não apenas não tem um autor, ou seja, um sujeito, mas também não tem sentido para o indivíduo, pois em nenhum lugar o reconhece naquilo que ele é para si mesmo. A luta das classes, portanto, representa a realidade social para o indivíduo. É por meio desse prisma que ele se dá conta disso e de seu efeito mais profundo, mais profundo do que o surgimento de uma consciência de classe, é a constituição para si mesmo de um indivíduo privado que, na forma de insatisfação, revolta ou simples recuo, mas geralmente no modo de insatisfação, está procurando uma linguagem com a qual possa expressar isso por si mesmo.

Podemos dizer, em outras palavras, que o indivíduo privado, que aparece em si com o tempo livre, aparece aqui para si, como um problema para si. Seu sentido de si mesmo é privado, porque privado de qualquer valor no nível social, isto é, no nível do discurso, da função e do cálculo. Para este discurso, todo "para-si" é, pura e simplesmente, indizível. 0 privado não é, portanto, um lugar, é temporalidade e consciência, é uma exigência: a exigência do tempo livre do trabalho e da objetivação como linguagem que me permite apreender e me colocar como sujeito livre, que dá sentido à minha objetivação do ser social, que a reduz ao seu estatuto de condição necessária, mas apenas de condição, para uma vida pessoal. Vemos, portanto, que o tempo livre, o lazer, circunscreve o privado, mas não é suficiente para constituí-lo e explicá-lo. O privado é mais exatamente o tempo da liberdade, o tempo do indivíduo que se afirma em sua posição de sujeito. 
Concluímos que o indivíduo privado é o homem moral, e precisamente o homem de reflexão moral universal. E a conclusão é correta, embora surpreendente. Weil escreve: "no sentimento de sua insatisfação, o indivíduo se encontra e se torna, como sujeito, sujeito de reflexão para si mesmo" (WEIL, 1956, p. 98). Aludimos, em conexão com Hannah Arendt, a uma analogia entre o estoicismo e o privado moderno. Também em Weil, a categoria do eu, que é a base da interpretação do estoicismo e de Epicuro, pode ser usada para compreender a situação atual do indivíduo ${ }^{9}$. Este indivíduo privado é jogado sobre si mesmo, na busca de uma satisfação que sua posição social não lhe assegura, da mesma forma que o registro do indivíduo na cidade não é mais suficiente, em determinado momento, para assegurar-lhe o contentamento humano. A categoria do objeto, na qual inclui Platão ${ }^{10}$, e a teoria que ela desenvolve pensam no contentamento na cidade, na realização do político. Mas esse contentamento é precisamente um acaso (cf. PLATON, République, 499 b), uma eventualidade, no sentido moderno da palavra, puramente teórico e remoto, que abandona o indivíduo à realidade atual de sua insatisfação: a conclusão ou a reconstituição do político ultrapassa o presente de sua existência. É por isso que o eu sai em busca de uma felicidade ao seu alcance, de uma felicidade para o aqui e agora, tarefa que é ao mesmo tempo a do indivíduo isolado pelo que deve ser chamado de fracasso político. Da mesma forma, o indivíduo está isolado, na sociedade moderna, porque tem uma relação crítica com os valores ou com a cultura de sua comunidade, e uma relação de distanciamento com sua função social. A realização e a feliz conclusão do social são um horizonte indefinidamente distante. A perfeição racional $d a$ sociedade (mundial), que de uma forma ou de outra fundamenta os projetos políticos, também ultrapassa a medida da existência individual, porque se realiza por meio do que ela suprime, a saber, o histórico, e porque a noção de progresso exclui a própria ideia de fim:

a sociedade remete o indivíduo a si mesmo: promete-lhe um futuro inteiramente racional, mas apenas promete. Esse futuro é um simples futuro, e a sociedade espera que no entretempo o indivíduo

\footnotetext{
${ }_{9}$ Com uma retomada, principalmente por meio da consciência. Sobre a categoria do eu, cf. WEIL, 1950a, p. 157174.

${ }^{10}$ Cf. WEIL, 1950a, p. 139-156. Com certeza, Platão não é o único autor compreendido nessa categoria, da mesma forma que esta não esgota a obra dele.
} 
se arranje como puder, isto é, segundo os valores que ainda conhece. Esses valores inevitavelmente levam-no a perguntar: para que tudo isto? (WEIL, 1956, p. 95)

O indivíduo moderno se vê lançado de volta à busca privada da felicidade, isolado na pseudonatureza social ${ }^{11}$, assim como o estoico se encontra sozinho diante da natureza. Mas a busca de satisfação não é, mais do que no caso do $e u$, a busca da satisfação particular da individualidade unicamente natural. 0 indivíduo privado se revela a si mesmo por uma estrutura social que é universal, criando condições que são as de cada indivíduo. 0 indivíduo, portanto, se apreende como um indivíduo universal, ele se apreende universalmente como um indivíduo privado. É também essa estrutura que exclui o recurso à violência e à satisfação puramente particulares. É por isso que "o sentido deve ser aceitável e acessível para cada um e válido para todos. 0 indivíduo que não recusa a sociedade e não renuncia às vantagens que ela lhe oferece não busca o sentido só para si, mas para todo si" (WEIL, 1956, p. 99).

O privado está, assim, profundamente enraizado em uma consciência temporal, que reivindica o presente da liberdade e do sentido contra o ainda-não e o entretempo do é progresso. Mas esta consciência é também uma consciência moral, que não desafia o mundo da condição, o mundo das determinações científicas e técnicas, mas exige compreendê-lo e dar-lhe sentido relacionando-o com os requisitos da vontade: “o que o homem opõe à natureza social é sua vontade de liberdade" (WEIL, 1956, p. 103). Se a vida do indivíduo privado se abre sobre esta exigência moral, ao contrário, é especificada no capítulo da Lógica da filosofia dedicado à consciência, que a vida do homem moral é a vida privada (WEIL, 1950a, p. 245), isto é, a vida na medida em que não é regulada pelo direito público, a vida com os parentes e, em última instância, a vida de consciência em relação às suas próprias intenções, visto que a moral tradicional indica claramente a definição concreta do dever na grande maioria dos casos.

Isso nos leva a especificar que o indivíduo privado não é rejeitado apenas pela forma pura de universalidade, mas pelos valores históricos tradicionais de sua comunidade: “o ponto

\footnotetext{
11 "A sociedade é uma segunda natureza para o indivíduo, conhecível e facilmente influenciada graças ao conhecimento das leis que descrevem seu funcionamento e com a ajuda das regularidades descritas por essas leis" (WEIL, 1956, p. 76).
} 
de vista a partir do qual a individualidade considera a sociedade e procura dar-lhe um sentido de uma moral viva" (WEIL, 1956, p. 105). 0 indivíduo privado é duplamente caracterizado por esta relação com os valores tradicionais e pela exigência de universalidade. Essa é a razão pela qual não voltamos pura e simplesmente ao ponto de partida, quando a moralidade histórica nos apareceu como o peso da história, como a definição concreta, estática e particular de uma comunidade, reduzida em certos casos à psicologia particular de uma população: mobilizados no sentimento de si de um indivíduo que se compreende como individualidade universal, os valores tradicionais são certamente concretos e particulares, mas agora percebidos em uma perspectiva evolutiva, movidos pela demanda de universalidade que garante seu significado propriamente humano. A reflexão do indivíduo privado sobre si mesmo, provocado e mediado pela linguagem da racionalidade técnica e social, por esse distanciamento em relação ao valor tradicional que inicialmente concebemos, é também a reflexão da tradição sobre si mesma que produz a universalidade formal como uma exigência inscrita em seu próprio conteúdo concreto. 0 retorno do indivíduo à sua própria tradição - a essa tradição que não existe "em outro lugar" a não ser no comportamento do indivíduo e na consciência que ele toma disso - prolonga e garante o movimento pelo qual essa tradição se universaliza. Portanto, ela não aparece mais como uma herança congelada do passado, mas como uma moralidade viva.

É claro, então, que a oposição do social e do privado é a oposição de duas morais, mais do que uma distinção de espaços, e mais essencialmente do que uma distinção de momentos. De repente, há uma oposição clara entre a abordagem fenomenológica de Arendt e a filosofia formal de Weil. Enquanto este último busca explicitar um certo número de estruturas e configurações, em particular espaço-temporais, para desenvolver seus significados, o que é primordial em Weil não é o ser-aí, mas o sentido que funda a organização espaço-temporal da vida porque orienta sua atividade, e que se dá a pensar ao filósofo na forma de sua coerência própria. É por isso que a tipologia de Arendt parece um tanto fixista, congelada. Além disso, ela visivelmente tem horror dos processos, das coisas que são fluidas. A análise de Weil restaura a atividade humana, a vida mais concretamente cotidiana, tanto em sua unidade quanto em sua complexidade, com suas interferências, suas sobreposições, sua polissemia permanente. As 
distinções weilianas são ao mesmo tempo reais e abstratas, reais porque refletem a orientação efetiva da atividade, e abstratas como distinções que são, cada uma para si mesma, uma tomada de visão do concreto. O lugar desses limites tão caros a Arendt é, em Weil, o discurso. Mas isso não significa que a vida humana seja, fora do discurso, um caos em si mesmo desorganizado, porque esta vida é precisamente humana e que o discurso é o do homem na sua vida: à coerência formal das categorias correspondem as coerências parciais e combinadas das atitudes efetivas $^{12}$

A oposição do social e do privado é, então, a oposição entre duas morais que são ao mesmo tempo universais e particulares. A moralidade social do trabalho, da eficiência e do cálculo vale para todos. E é realmente uma moral que exige honestidade, seriedade no exercício da função, respeito pelo direito positivo que garante a paz social. A moralidade viva exige que essa ordem e esse mecanismo social tenham um sentido para qualquer indivíduo caracterizado como sujeito, e como sujeito livre, ou seja, como um fim em e para si mesmo. E a oposição é real, porque a primeira dessas morais é fundamentalmente desigual: ela introduz o princípio da competição entre indivíduos reificados, objetivados. A segunda é fundamentalmente igualitária, pois considera os indivíduos como sujeitos livres. Não pode haver competição pela liberdade, mas apenas reconhecimento recíproco.

Se permanecermos neste estado da questão, podemos protestar: o indivíduo que nos é apresentado aqui é definitivamente um indivíduo muito reflexivo. E vamos pôr em dúvida esse conteúdo do privado, que é uma moralidade viva em busca de sua universalidade. A vida privada do cidadão comum [Monsieur tout-le-monde] é uma realidade mais comum e mais imediata. Mas a objeção cai facilmente. Em primeiro lugar, no que se refere ao requisito da universalidade, ela não é formulada como o é por todos os contemporâneos, mas isso não a impede de ser presente e ativa. Esta observação nada mais faz do que sublinhar a realidade Greco-cristã da moralidade ocidental, que análises sociológicas, históricas, etc. facilmente confirmariam. Por outro lado, Weil sabe muito bem que a consciência moral não é a única consciência privada.

\footnotetext{
${ }^{12}$ Sobre os conceitos de atitude e categoria, cf. WEIL, 1950a, p. 70-72 e 79-82. Cf. igualmente CAILLOIS, 1953.
} 
Podemos ainda nos referir à cultura desinteressada da inteligência, no tempo afastada do exercício de uma função, mas também podemos nos referir às análises da condição, que dão uma interpretação filosófica da distração, do consumo cultural, da relação dos indivíduos com música, romances, etc. (cf. WEIL, 1950a, p. 225-227). 0 indivíduo privado, como poderíamos entendê-lo na categoria da condição, não se pensa como sujeito livre porque não pode fazê-lo em função da sua própria atitude: sua vida privada será, portanto, justificada, com base em considerações de ordem psicológica e funcional. E não há uma progressão necessária para a atitude da consciência moral: "ninguém jamais pôde dar uma consciência moral a alguém que fosse (ou se julgasse) dela destituído" (WEIL, 1950a, p. 246). Isso significa, em termos lógicos, que a vivência da luta das classes sociais só possibilita a passagem da atitude da condição para a da consciência, da atitude puramente funcional e técnica para a da consciência moral. Se esta passagem é uma passagem dedutiva na Filosofia Política, é porque o sujeito que progride na reflexão se compreende desde o início como consciência moral. Trata-se, portanto, de uma dedução a posteriori de um sujeito que faz a história a partir da sua atitude ou, se preferir, de seu modo de inserção na sociedade moderna. 0 sujeito moral aprende então que ele não é apenas igual a todos enquanto sujeito livre, mas também em sua situação concreta de indivíduo ao mesmo tempo social e privado. Então fica claro o que o identifica e o diferencia de todos os outros indivíduos privados. 0 princípio da identidade é o problema moral; o princípio da diferença é o da formulação e tratamento deste problema pela reflexão. Como o filósofo apreende o todo da estrutura, ele reconhece o problema moral como ele é e o reconhece como o de cada indivíduo privado. Para quem está "preso" na estrutura o problema se põe, mas como insatisfação, preocupação, incômodo ou tédio, resolvido nas e pelas linguagens que o indivíduo encontra à sua disposição e que são, na maioria dos casos, retomadas mais ou menos complicadas da condição. Essas linguagens põem e resolvem o problema moral de maneira inadequada, mas significam, por meio dessa discrepância, a realidade ativa do problema. Podemos nos referir às análises de Weil sobre a toxicodependência, sobre certas patologias nervosas, a violência gratuita, etc. ${ }^{13}$

\footnotetext{
${ }^{13}$ Em particular, "L'éducation en tant que problème de notre temps" (WEIL, 2003, p. 297-310).
} 
Essa diferença e essa identidade, paradoxalmente, explica a possibilidade de permanecer na atitude da moral pura - possibilidade recordada na primeira parte da Filosofia Política e de pensar a ação política. Isso porque a conciliação das duas morais não apresenta dificuldades insolúveis do ponto de vista reflexivo e teórico que é aquele da moral pura. Essas duas morais implicam uma à outra: a moral social é a condição de possibilidade e mesmo um pré-requisito educacional para a moral da universalidade. Mas, ao mesmo tempo, sem essa moral do sentido, deixado apenas aos seus valores técnicos, o mundo social logo entraria em um colapso de violência e tédio. Essa reciprocidade, que é, em última análise, a do entendimento e da razão, é claramente perceptível para esse indivíduo privado e consciente de si que é o filósofo. Mas, precisamente, essa reconciliação teórica é o problema e a preocupação de um indivíduo privado, desse indivíduo que é o filósofo. Weil escreve:

a consciência do filósofo é a consciência do mundo moderno; mas é a consciência privada de um mundo inconsciente do problema da individualidade, um problema que permanece inacessível e inaceitável para este mundo. Neste mundo, a universalidade desta individualidade constitui uma particularidade, e a referência à moralidade viva nada significa para aqueles que não colocam a questão do sentido e não podem fazê-lo porque têm outras preocupações. (WEIL, 1956, p. 118)

O filósofo torna-se assim plenamente consciente do caráter privado de sua situação. A conciliação é pensável, o que significa que o mundo tem uma unidade. Para aquele que está preso neste mundo, a realidade fundamental continua sendo a da luta nas sociedades históricas (luta entre classes sociais) e entre elas (WEIL, 1956, p. 117). A unidade, real no pensamento do

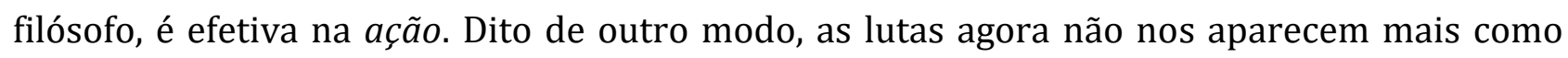
simples conflitos sociais, com questões econômicas e técnicas, elas mobilizam também valores, porque os indivíduos que se encontram nessas lutas querem algo para sua existência pessoal. O conflito e a inextricabilidade do cálculo e do sentido, do justo e da eficácia, é a estrutura fundamental do mundo humano que agora aparece como um mundo político, porque essa conciliação é tarefa própria do Estado (WEIL, 1956, p. 179-221). É a ação que dá a unidade do mundo e que é a universalização efetiva dos valores, notadamente por meio da discussão política, como o mostra a análise weiliana do Estado constitucional (cf. WEIL, 1956, p. 129-179). Essa ação é 
compreensível apenas porque a unidade e a universalidade foram pensadas, teorizadas no privado da reflexão filosófica. Mas esse privado, quando apreendido como tal, revela precisamente o caráter privado desse processo. É então que, em contraponto à atitude teórica, se mostra a realidade da ação e a necessidade de pensar sobre ela. Em outras palavras, todo indivíduo privado é livre em-si mesmo, não necessariamente para-si mesmo. 0 filósofo o é em-si mesmo para-si mesmo, mas apenas, por assim dizer, como um indivíduo privado. Ele deve, portanto, querer a universalidade efetiva desse para-si mesmo, porque ele entende, como diz Weil, "que ele será igual a todos quando todos forem iguais em razão" (WEIL, 1956, p. 35).

A Filosofia Política, portanto, tematiza claramente o fato de que um filósofo se dirige a alguém que concordou em filosofar. Primeiro, porque o leitor se reconhece nesta consciência moral, nesta moral da universalidade que constitui o ponto de partida da análise. Mas também em outro sentido absolutamente fundamental: o privado que descubro ao ler o livro é o meu próprio privado preenchido com essa leitura. De modo que a abordagem a que Weil nos convida é verdadeiramente reflexiva: o filósofo é filósofo porque dispõe de tempo, porque gosta eminentemente de sua existência privada, e a Filosofia Política o convida a uma reflexão concreta sobre sua situação, aqui e agora, no mundo social ${ }^{14}$. 0 desenvolvimento formal nos traz de volta, como sempre, com este autor, ao mais próximo do concreto. Desde o início, é posto o que se prefigura apenas ao final de $A$ condição humana: a tematização da consciência pensante e sua inserção no social. 0 resultado desta reflexão, ao mesmo tempo concretamente individual e universal, formal, é que o filósofo não pode perder de vista que as suas soluções são soluções privadas. Isso não significa que não tenha função social. Isso não exclui que hoje ele tenha uma função enquanto filósofo - toda a Filosofia Política diz o contrário -, mas essa função social só é compreensível quando o privado de liberdade filosófica se mostra como tal. É então que ele chega à política. Não na política que ele entende como um acidente ou condição que encontra, como todas as outras, em seu mundo, mas na política como a realização efetiva da conciliação

\footnotetext{
${ }^{14}$ Podemos assim explicar que o privado não se funda na natureza, com Weil, uma vez que é, em última instância, o privado do sentimento, que pode ser refletido e que se reflete efetivamente na leitura da obra ou, em geral, na atividade compreensível. Em relação a isso, é secundário e indiferente que o lugar do privado seja o da família. É o indivíduo que pensa.
} 
da qual ele produziu a teoria. Podemos, portanto, ver um dos aspectos da relação da filosofia com a ação: a conciliação teórica das contradições é necessária e insuficiente - aliás, como toda categoria. É insuficiente porque não realiza efetivamente aquilo que pensa. É necessária não só para pensar em conciliação efetiva, mas muito simplesmente para percebê-la. A conciliação está presente no mundo e não apenas no pensamento do filósofo. Mas, ao mesmo tempo, essa ação não leva a nada além do que o filósofo pensava. No entanto, precisamente porque ela o realiza, ela exige que ele pense sobre a realização mesma, a ação, e não apenas a ideia. Em seguida, passamos para a terceira parte da Filosofia Política, vislumbrando o vasto problema da relação de Weil com Hegel e com Marx, e de sua concepção da passagem de um para o outro.

Há aqui novamente um ponto em comum entre Arendt e Weil, e isso nos leva a concluir: a posição de Arendt também é reconhecida como o privado da compreensão (ARENDT, 1985, p. 181). Mas, por um lado, trata-se de compreender uma ação essencialmente frágil, efêmera, ressurgente aqui e ali nas revoluções americana e francesa, na Resistência ou na revolução húngara de 1956: um espaço libertário de discurso afastado de qualquer sistema, longe da administração e da organização, que se cria numa espécie de espontaneidade e parece sempre destinado a desaparecer, até por causa do Estado, como é evidente no Estado totalitário. Por outro lado, a ação é a própria realidade do Estado (cf. WEIL, 1956, p. 129-139), uma realidade efetiva, muito mais concreta do que a sociedade e a intimidade do privado, porque as duas se sobrepõem nela.

Podemos ver que grande parte das divergências de apreciação repousam sobre diferentes análises das relações entre o político e o econômico. Weil busca reconciliar a hierarquia e a igualdade, a ordem vertical do social e a igualdade implícita na liberdade moral e política. Para Hannah Arendt, os dois se excluem irremediavelmente. Esse problema é central para ambos os autores: ele rege o que se poderia chamar de questão do futuro da política. 0 mínimo que se pode dizer é que mostra a que ponto Weil e Arendt são atuais, em uma época agitada pela questão de saber se o programa de um determinado partido é propriamente político ou se o político, para retomar a bela palavra de Arendt, "evaporou" nele. 
Notamos diferenças no método. A palavra "método" pode ser fraca ou inadequada. Há, no espírito de Hannah Arendt, uma divergência radical entre as orientações da filosofia e as de sua prática teórica. No decorrer de sua entrevista com Günter Gaus ${ }^{15}$, ela disse de fato: “Quero ver a política com olhos que sejam, por assim dizer, puros de toda filosofia”. A filosofia é suspeita de uma hostilidade tradicional à ação, de substituir a lógica das ideias pela livre emergência das coisas. Mas não é um dos menores paradoxos da comparação que nos leva a pensar, ou a notar, que a fenomenologia resulta em certo formalismo, que substitui a lógica da descrição, ou mesmo da metáfora, pela complexidade da coisa descrita. Resta que a dificuldade surge da própria fecundidade das análises de Arendt e poderíamos citar à vontade os esclarecimentos decisivos trazidos por sua distinção entre trabalho, obra e ação, não apenas para a percepção de nossa situação atual, mas sobre o alcance e as intenções de teorias políticas ${ }^{16}$. 0 formalismo de Weil, por sua vez, nos remete à efetividade de nossa situação concreta, como se o concreto não devesse ser descrito tanto quanto experienciado na atualidade de uma tarefa ${ }^{17}$.

Em todo caso, há um ponto em comum que nos parece dever ser bem discernido por meio dessas divergências. 0 político é, para Weil e para Arendt, um espaço de igualdade e de diferenças, um espaço de discussão livre, um mundo de linguagem livre do domínio de um senhor. Parece que, em Weil como em Arendt - e a impressão seria reforçada pela análise dos textos de Weil sobre o diálogo ${ }^{18}$ - um dos desafios da atividade do teórico e do filósofo é salvar o político. É a esse desafio que devemos relacionar as nossas constatações metodológicas, recolocando o problema do modo de intervenção do pensador no Estado. Vemos que o horizonte da busca é constituído por esta questão, que concerne ao filósofo da mesma forma que envolve a todos os outros: o que é agir?

\footnotetext{
${ }^{15}$ Entrevista para a televisão transmitida no segundo canal de televisão alemã, em 28 de outubro de 1964.0 texto dessa entrevista, várias vezes publicado, encontra-se reproduzido também no número da revista Esprit especialmente dedicado a Arendt.

16 Cf., por exemplo, a análise da política platônica em Condition de l'homme moderne, p. 249 ss.

${ }^{17}$ Deste ponto de vista, é preciso fazer uma distinção entre a Philosophie politique e os Essais et conférences. Podese referir, por exemplo, às análises de "Masses et individus historiques" (WEIL, 1991b, p. 255-325), que é o que se poderia chamar de texto da atualidade.

${ }^{18}$ Cf., por exemplo, "Vertu du dialogue”, em WEIL, 2003, p. 279-310.
} 


\section{Referências}

ARENDT, H. Condition de l'homme moderne. Paris: Calmann-Lévy, 1983.

ARENDT, H. A condição humana. Trad. R. Raposo. 11 ed. São Paulo: Forense Universitária, 2014.

ARENDT, H. La Crise de la culture. Paris: Gallimard, 1989.

ARENDT, H. Entre o passade e o futuro. Trad. M. Barbosa. 7 ed. São Paulo: Perspectiva, 2011.

ARENDT, H.; GÜNTER, G. Seule demeure la langue maternelle. Esprit, 6, juin, 1980, p. 19-39.

ARENDT, H. Le grand jeu du monde. Esprit, 7-8, juil./août, 1982, p. 21-29.

BARAQUIN, A. Hegel et l'Etat. In: KIRSCHER, G.; QUILLIEN, J. (Ed.). Sept études sur Weil. Lille: PUL, 1982, p. 27-55.

CAILLOIS, R. Attitudes et catégories selon Eric Weil. Revue de Métaphysique et de Morale, n. 58, 1953, p. 273-291.

DEPADT, M. L'intelligence dans la Logique de la philosophie. In: KIRSCHER, G.; QUILLIEN, J. (Ed.). Sept études sur Weil. Lille: PUL, 1982, p. 75-99.

DEPADT, M. L'intelligence ou le contre-sens du sens. In: Actualité d'Eric Weil. Paris: Beauchesne, 1984, p. $175-181$.

ENEGRÉN, A. La Pensée politique de Hannah Arendt. Paris: PUF, 1984.

FINLEY, M. L'Invention de la politique. Paris: Flammarion, 1985.

SALEM, J. Eric Weil, lecteur de Marx. In: Actualité d'Eric Weil. Paris: Beauchesne, 1984, p. 387-395.

WEIL, E. Philosophie et Réalité 1. Paris: Beauchesne, 2003.

WEIL, E. Essais et Conférences 1. Paris: Vrin, 1991a.

WEIL, E. Essais et Conférences 2. Paris: Vrin, 1991b.

WEIL, E. Hegel et l'Etat. Paris: Vrin, 1950b.

WEIL, E. Hegel e o Estado. Trad. C. Nougué. São Paulo: É Realizações, 2012.

WEIL, E. Logique de la philosophie. Paris: Vrin, 1950a.

WEIL, E. Lógica da filosofia. Trad. L. C. Malipensa. São Paulo: É Realizações, 2012.

WEIL, E. Philosophie politique. Paris: Vrin, 1956.

WEIL, E. Filosofia política. Trad. M. Perine. São Paulo: Loyola, 1990.

Recebido em: 29/9/2021

Aprovado em: 23/12/2021

\section{Patrice Canivez}

Professor de filosofia moral e política, diretor do Institut Eric Weil (http:// ericweil.recherche.univ-lille3.fr/) e diretor do departamento de filosofia da Université Lille 3. Além do seu trabalho sobre Eric Weil, ele realiza pesquisas sobre outros autores (Aristóteles, Rousseau, Hegel; H. Arendt, P. Ricoeur, J. Habermas) e sobre 
temáticas contemporâneas: a educação na democracia, o Estado-nação e o nacionalismo, a argumentação política e a questão do compromisso etc. 